\title{
Can 100 must-read papers also reflect 'who' is ecology?
}

To the Editor - Professors everywhere are challenged to guide new ecologists into the essential scholarly literature, and I applaud Courchamp \& Bradshaw' ${ }^{1}$ effort to define an "objectively chosen and ranked" set of ' 100 articles every ecologist should read' using editorial boards from ecological journals. However, any such guided journey must not only represent what is ecology but also who is ecology. Perusing the authors of the 100 articles revealed dramatic gender imbalance. I could confirm the gender of only 172 of the 174 authors, but only seven of 100 papers included any women authors (numbers 31, 77, 82, 86, 89, 99 and 100), and only the last two had female first authors. Women thus represent only $4.6 \%$ of the authors of the top 100 papers. At the same time, 19 of the male authors appear multiple times, collectively accounting for $39 \%$ of all authors. Even more striking, Robert May (ten papers), Robert MacArthur (eight) and David Tilman (eight) each had more articles in the list than all female ecologists combined.

The historical gender bias among ecologists and publishing patterns ${ }^{2}$ ensures any objective 'must read' list of the literature would show a male-dominated imbalance, but with women representing more than half of the younger members of the 10,000 members of the Ecological Society of America $^{2}$, this gender imbalance and strong dominance by a few researchers was jarring. Courchamp \& Bradshaw examined gender balance among the proposers and voters as potential sources of gender bias; however, I found it curious that they did not discuss the strong gender imbalance in the authors of selected papers, nor the repeat appearances by a small number of ecologists.

One might ask if the content of each article uniquely represents a foundational advance in ecology, or whether some are alternative representations of important bodies of work by eminent ecologists. For instance, drawing from my own area of disease ecology, I wonder whether four classic papers by Anderson \& May (numbers 42, 88, 95 and 98) on host-parasite population biology each need to be read by all ecologists "regardless of particular topic or expertise". One of these papers might provide adequate introduction to the body of critical insights by these ecologists. The voting process, although designed to maximize inclusion, may well have contributed to selection of multiple papers by prominent authors. By presenting each voter with a random set of 20 of the 544 proposed articles, each voter would have about a $12 \%$ chance of receiving exactly one of the four Anderson \& May articles in a given slate (and 1.7\% chance of more than one). Most ecologists would probably agree with the foundational importance of this body of work to disease ecology, and would vote for any one of the four articles that appeared on their slate, but they would rarely have to choose between two. In the process, all four articles would probably be voted to inclusion. This may be one reason why so many men appear multiple times - potentially at the expense of women ecologists who made foundational contributions and constitute an important component of who is the ecological community.

Others have creatively and critically examined the persistence of gender imbalance in publications in ecology $y^{2,3}$, and Melissa Giresi's ${ }^{4}$ Twitter-based list of the 45 most influential living female ecologists provides a wonderful entry into contributions of women in the ecological scholarly community. By combining consideration of who represents ecology with what is essential to include, we may come closer to a robust list of articles that every ecologist should read.

\section{Gregory S. Gilbert}

Environmental Studies Department, University of California, 1156 High Street, Santa Cruz, CA 95064, USA.

e-mail: ggilbert@ucsc.edu

Published online: 14 December 2017

https://doi.org/10.1038/s41559-017-0444-8

\section{References}

1. Courchamp, F. \& Bradshaw, C. J. A. Nat. Ecol. Evol. https://doi.org/10.1038/s41559-017-0370-9 (2017).

2. Martin, L. J. Front. Ecol. Environ. 10, 177-178 (2012).

3. Langenheim, J. H. Annu. Rev. Ecol. Syst. 27, 1-53 (1996).

4. Giresi, M. The 45 most influential female ecologists alive today according to Twitter. Southern Fried Science (20 November 2017).

Competing interests

The author declares no competing financial interests. 